\title{
Relationship between Professional Ethics and Organizational Commitment
}

\author{
Freyedon ahmadi \\ Department of public management, Payame Noor University, Tehran, Iran \\ E.mail: freyedon@yahoo.com
}

Accepted: October 16, 2011 Published: December 04, 2011

Doi:10.5296/ijld.v1i1.1139ＵRL: http://dx.doi.org/10.5296/ijld.v1i1.1139

\begin{abstract}
The purpose of this paper is to investigate relationship between professional ethics and organizational commitment in food industry in Kurdistan province. In this study researchers have used the Allen and Meyer's model for identification of organizational commitment. For accessing the objective sample of 210 people of 15 food industry in Kurdistan province was selected. The results of this study have shown that, there is a significant relationship between professional ethics and organizational commitment and its dimensions.
\end{abstract}

Keywords: Organizational commitment, affective commitment, continuance commitment, normative commitment, Professional ethics

\section{Introduction}

Ethics is a necessity for healthy society. Scientists, trainers, and managers of organizations always pay attention to ethics because of its positive individual, organizational, and social efficiencies and results.

The constant values and ethics in organizations of society which in fact is the essential device to solve the social problems, is the central point of organizational manner and edification of ethics as our management's base is necessary for mange the separated organization of it (Kia, 1994). In past, financial results were important reasons to realize a good company. But in recent years, Morals, work quantity, and work satisfaction are increasingly identified as development standard associated with performance and persistence of commercial organizations. Increasing of complexity of commercial competition and hard using process of effective social rules introduce the ethics as an 


\section{Ml Macrothink}

essential strategic factor in keeping out the companies from unwilling failure . So, the good behavior is the same good trade. The good behavior causes appreciate, admiration, affection, and interest that act respectively as reinforcing power to guarantee the continuation (Nayer , 2011). Personnel's prefer to in Ethics organizations, because a moral work environment decrease colleague work unpleasantness increase of work satisfaction, and improve the psychological relationship among colleagues (valentain , 2010). Furthermore, most of the people are concerned about ethics problems when they want to decide an important issue like accept of job applicants or when customers buy a crop (Kalshun, 2011).

Commitment is one of the main ethics bases in the society. Because of this reason, this concept has essential rout in all of the morals theories. The personnel who have organizational commitment have more efficiency in doing their work in comparison to non-aligned personnel's (Foldman , 2011). On the other hand, so many factors can be effective in creating commitment and adherence among personnel's. According to researcher's studies some factors like job sates frication, job security, decision - making, values of personnel's, have been known as effective factors on organizational commitment. In this article the question is that, is there any relationship between professional ethics and organizational commitment? As a result, according to the above mentioned concepts to determine that whether the existence of relationship between professional ethics (independent variable) and organizational commitment (dependent variable) and all of its dimension from the viewpoint of Allen and Meyer has validity to consider as a hypothesis or not, this study has been done to clear its validity by scientific method.

\section{Review of theoretical principles:}

\subsection{Professional Ethics:}

In the beginning, professional ethics was used as work morals and jobs ethics, and nowadays some of the authors used professional ethics in its first concept. There are some different definitions about professional ethics:

Morals are common behavioral methods among members of a profession.

Ethics is the management of human behavior during professional activities.

Ethics is a major of ethics that studies occupational relationships.

In all of those definitions the perception is individual nobility or individuality and professional morals associated to responsibilities and ethics. Because, organizational and collaborative identity in busy (working) organizations is more complex in occupation rather than individual job. So, organizational morals have an extended definition rather than job. Therefore, define of professional morals needs the analyzing ethics and profession. What is the difference between profession and occupation? Is professional ethics as the same business ethics? The answers to these question the importance of ethics and professions definition.

2.1.1. Ethics means mood, nature, temper, and such things which is used as inner part of human and it can be understand by insight in comparison to "people " which is used to 
appearance of human and it can be see with eyes. Also ethics has been defend as the collection of human spiritual and inner characteristics which arise from inner features of human and because of this reason it had been said that ethics can be defined according it's effects. Continuation of a specific manner shows that this manner has an inner root in person's life and spirit which called morals . the area of morals is considered as individual behavior, but individual behavior when develops to social behavior has changed to collaborative morals that affects on culture and society, and this society can be known according that .Kant believe that, the ethics value does not result along with interest and benefit, but it is against and profit. If everybody pays attention to the output interest and profit of something that hellish is doing, that activity will lose its ethics value. The human motivation to do something must be follow of conscience, and if it was not the matter that activity will has not ethics.

2.1.2. Profession: the common use of profession means job, occupation, and business . The colloquial concept of profession is differ from job and salary from so many year ago. Pay attention to difference between those two words can be helpful.

For example, slavery is not a profession but slaves work. Brigandage is not a profession even though brigands work, too. Working to get interest is not a profession. Feridsen believes that reaches to professional status and this process join to social conditions (feridsen, 2001) Ghadvik believes that, "profession is a special kind of activity that person by that benefit specific status and safety and will belong to special custom and morals. Based on this reality, Davis believes that, If workers and clerks do their tasks well, they become professional, too (Ghavdik, 1998)".

Now we can analyze the professional ethics conceptually after describing the morals and professional. The above - mentioned materials showed that, professional ethics is not custom and features of professional people and while occupational ethics is a branch of society culture which follow some job opinions and values of main general rules dominate on society, culture an often it is related to conservative policies. Professional ethics is a branch of applied ethics that considers ethics issues in profession. Therefore, professional ethics is defined as person's ethics responsibilities and organization in doing profession. This definition is more comprehensive and complete than traditional definition. Because ethics responsibilities of organization included all of its dimensions and job ethics. While job ethics because of group's members, group's ethics responsibilities, and organization. Furthermore, these definitions are based on person's nobility view they ignored to consider the important of group and organization's life. Therefore, emphasizing on organization's morals responsibilities is based on the overall objective and systematic view at first, then it gives a comprehensive definition of professional ethics.

\subsection{Organizational commitment:}

Organizational commitment, especially organizational behavior is one of important issues of management that has been considered recently. Not only, studies that are directly associated whit making commitment and its results, have been developed, but also in most 


\section{1) Macrothink}

of the studies that were not base on commitment, commitment has been considered as a variable.

Commitment means loyalty and situation that based on person has a positive and absolute feeling to something (Ferench, 1992). Buchanan defined commitment a "commitment is an emotional and fanatical dependence to values and purposes of an organization". Commitment means and dependence to person's role in relation to values and purpose of organization because of himself or herself sake. Garment and orally are believed that organizational commitment means emotional protection and dependence with purposes and values of an organization because of organization itself and avoid of its device. If people consider themselves as mercenaries who are engaged in an expensive auction, the result of work will be very expensive. The mercenaries and salaried will only be committing about accepted pan and they do not have any loyalty and commitment to organization (Hendi, 2001).

Committed personnel's are more eager to have noticeable records and keeping the job for a long time than less committed personnel's. Furthermore, committed personnel's are more willing to try more to do their tasks and better performance than less committed personnel's. Briefly, there are considerable evidences that show, committed personnel's (Desler, 2000).

From another view, organization Committed is a kind of dependence and belonging to the organization. Sheldon defined the committed as a kind of wiling and orientation to organization that join the person's identity to organization. It is a situation that a person in an organization knows his / her purposes as her / his introducer and helter hope that to remain as a member of that organization.

There is a reverse relationship among personnel's organization commitment, absence, and transfer . The most complete research about organization commitment and it's dimensions has been done by Allen and Meyer. These two researchers define organization commitment as:" a psychological manner that is an indicator of kind of willing (affective commitment and continuance commitment) and necessity to be engaged in organization (Normative commitment). Meyer and his colleagues are the pioneers of multisession. Affective dimension, continuance dimension, and normative dimension are three dimensions of organization commitment that construct Meyer and his colleagues. 


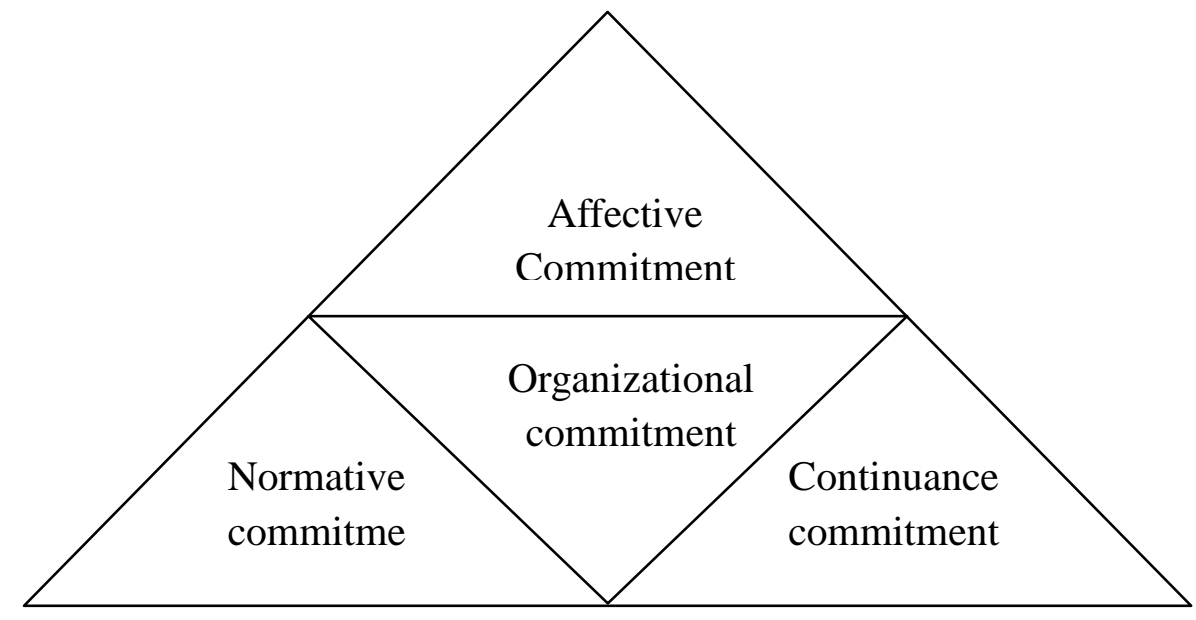

Figure 1 .different dimensions from the viewpoint of Allen and Meyer

\subsubsection{Affective commitment:}

Allen and \& Meyer know the affective commitment as emotional dependence of person to organization and are identity assigned by that. Allen and Meyer are believed that, a person feels emotional dependence to organization when he/she knows the goals of organization as his/her goals and be convinced that he/she must help to organization to reach its goals. They also mention that, be identity assigned by organization occur when the personal values of personnel's adapt with organization values as the person be able to make organization value intrinsic. Undoubtedly, there is a psychological relationship in identity determination by organization and person feels proud because of identity determination by organization (Allen \& Meyer, 1990).

The effective variables on Allen \& Meyer's model:

The scientists of organization behavior and researchers who are studied about organization commitment, were tiring to prove that, what kinds of parameters affect on his/her organization commitment after his/her entering to organization.

Variables which have relationship with affective commitment:

According to Allen, Meyer, and their colleagues, different variables that affect on affective commitment can be divided into three categories:

\subsubsection{Personal characteristics:}

By reviewing organization commitment we can conclude that personal characteristics that have considerable effect on organization commitment and are generally consist of 
population characteristics are, age , tenure, gender, family status, educational level, and also all of the personal characteristics such as need for achievement, sense of professionalism, and skill.

\subsubsection{Organizational characteristics:}

Organizational characteristics such as construction, culture, strategies, and Organizational policies that improve personnel's understanding to help to Organizational will develop organization commitment.

\subsubsection{Occupational experiences:}

Allen and Meyer concluded that different experiences which make the personnel's physically and psychologically calm, lead to affective commitment. These experiences are consisting of protection understanding on behalf of Organization. So personnel's who feel that ,they increasingly protect on the side of organization, will have serious feeling to answer to that kind of organizational protection (Meyer, Allen \& Larissa, 1998).

\subsubsection{Continuance commitment:}

The second dimension of Allen and Meyer's organizational dimensions is continuance commitment which is based on best investment theory. This theory is based on this reality that person gradually save an investments in organization. The more people's experiences in organization, the more investment, and losing it are costing for person. This investment is included of time; obtain particular skills of organization which are not transferable, job friendships, political factors, and other costs that discourage person to look for substitution works (Allen \& Meyer, 1991).

Continues commitment indicates the person's decision to continue participation in organization, because of expected costs of living the organization. The effective factors on continuous commitment can be classified in two categories of official variables: investments and employment alternatives.

\subsubsection{Investments:}

Whenever person understands that he or she will loses some advantages if he / she leaves the organization he/she will prefers to stay in organization. Person's investment can be related to work or cannot be related to it. Work investment can be included the spend time to obtain non-transferable skills, losing the probable advantages, losing a great position, and different related advantages to it (Meyer \& Allen, 1990). 


\section{Al Macrothink Institute ${ }^{\mathrm{TM}}$

\subsubsection{Substitution occupational occasions:}

Understanding of an employee about substitution occupational occasion has negative relationship with continue commitment. So personnel's who think that have many substitutions for their positions, have less continues commitment than personnel's who think they have few substitutions for their positions. Ramzak (990) believed that, organizations can easily create that feeling in their personnel's who have invested highly for them in organizations must only suggest occupational conditions and occasions that be competitive to other employers conditions. Among those investment standards can point to promotion expectation, establishment of occupational network group, rewards salary, and retirement's advantages. If employers cannot create those factors for their employees, employees will leave the organization. Meyer and Allen (1997) emphasize on this reality that, investments and substitution occupational occasions do not have any effects on continues commitment since the employee dose not be aware of the results of losing the investments and lack of substitution occupational occasion. Therefore, the person's understanding of this reality that losing the replete investments and lock of substitution occupational occasions cause the leasing of the organization more expensive will result in development of continuous commitment. According to the opinions of Meyer and his colleagues (1989), this reality that understanding or realizing plays central role in this process make clear two points for us: first, people who are in the same condition can have different levels of continuous commitment. Second, to effect on continuous commitment must draw personnel's attention to variables that are related to cost.

\subsubsection{Normative commitment:}

The third dimension of organization commitment is normative commitment which is the indicator of a responsibility to continue collaboration whit. Those people, who have high level of normative commitment, feel that they are forcing to stay in present organization (Allen \& Meyer, p.14, 1997).

Normative commitment is formed based on an especial organization s investment on person that its compensation is hard. For example, if an organization pays the training cost of its employees (like scholarship and ...), he/ she may feel embarrassed and debt to organization and employee may feel a duty to stay in organization and compensate the, investment. In this respect, we must remind that, individual and cultural differences are effective to personal duty (Meyer \& Allen, 1997). In comparison to affective and continuous commitment, a few factors have been known. According to Allen and Meyer's opinion, normative commitment is formed base on a psychological contract between person and organization; a psychological contract which is related to mutual commitment. Some of the person and organization's communications can be classified into negotiation contracts that are based on economical exchange bases; the salient sample of that is work contract. Another example is official and written contract that can be named as communicative contract. Negotiation contract is more real and is based on economical exchange basses. Instead, the communicative contracts are more abstraction and are based on social exchange 
based. This social exchange is formed in society acceptance and entering of person to organization, and during that, the organization's expectations from that person will be determined. Negotiation contracts have more effect on continues commitment while communicative contract is more related to normative commitment.

\section{Conceptual Model and research hypotheses:}

According to the theoretical bases about professional ethics and three dimensional model of organizational commitment from the viewpoint of Allen and Meyer, the conceptual model of researcher has been studied and presented by researcher as follow:

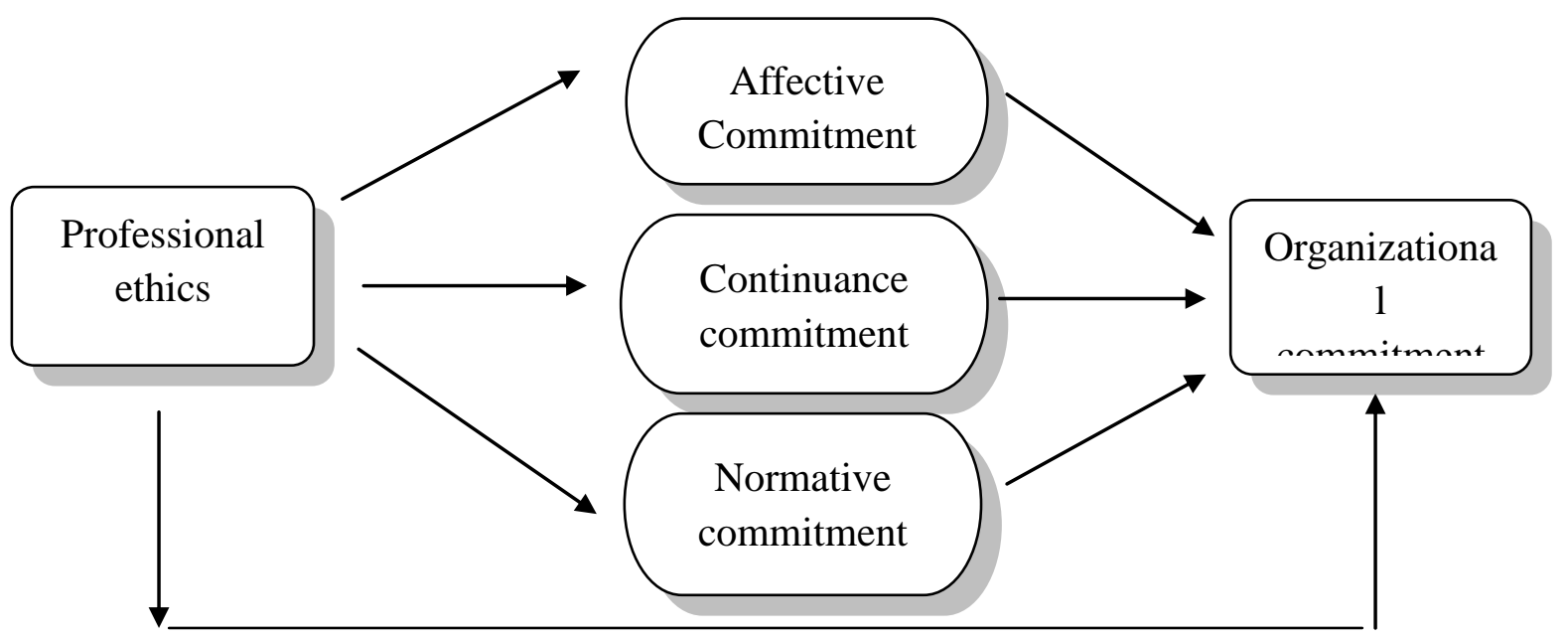

Figure 2. The conceptual model of research based on theoretical based

According to the conceptual model of project, the following hypotheses are main axis of have been done studies in this project:

The main hypothesis:

There is a significant relationship between professional morals and organizational commitment.

Minor hypotheses:

1. There is a significant relationship between professional morals and affective commitment.

2. There is a significant relationship between professional morals and continuous commitment of personnel's.

3. There is a significant relationship between professional morals and normative commitment of personnel's.

\section{Methodology:}

\subsection{Procedure:}

The purpose of present research is applied, because it is looking for reach a scientific purpose and its results are useable for different groups of planners and managers. It is a 
correlation study on the side of the analysis and type, because it is looking for find the relationship between professional morals (independent variable) and organizational commitment of personal (dependent variable) in food industry. The way of collecting information is descriptive because it is doing without reforming the variables and their components.

\subsection{Research domain and population:}

The population of this research is consisting of all of the official employees in food industry in Kurdistan province. According to the obtain information from planning unit, all of the 10 food industry personnel's were 418 persons. 210 people were selected as sample.

\subsection{The tool of collecting information:}

The main tool of collecting information was questionnaire in this study. Level questionnaire was used to evaluate the professional ethics and Allen and Meyer (1990) questionnaire was used to evaluate organizational commitment and it's dimensions which is used increasingly to evaluate all of the components of affective commitment, continuous commitment, and normative commitment.

\subsection{Analyzing the data:}

To analyze the collected data by questionnaires of project, the descriptive statistic and perceptive statistic method have been used. The descriptive statistic that has been used in this study is included means, standard deviation, maximums, and minimums. The perceptive statistic is included of correlation of pearson which by using that coefficient, the relationship between professional ethics and organizational commitment and all of its dimensions have been studied. The efficiency level of $\alpha=\% 5$ has been considered and data was analyzed by using spas software, the 16th copy.

\section{Results of project's hypotheses:}

Hypothesis (1): there is a significant relationship between professional ethics and organizational commitment of personnel's.

Statistical hypothesis:

There is not significant relationship between professional ethics and organizational commitment among personnel's; $H_{0}: B_{1}=0$

There is a significant relationship between professional ethics and organizational commitment among personnel's; $H_{1}=B_{1} \neq 0$

According to this fast that both variables have been measured in timed level, so correlation 
coefficient of parson has been used to test the hypothesis and results are as follow:

Table (1). Related table to correlation coefficient between professional morals variable and organizational commitment among personnel.

\begin{tabular}{|l|c|l|}
\hline \multicolumn{2}{|l|}{ organizational commitment (dependent variable ) } & \multirow{2}{*}{$\begin{array}{c}\text { Professional ethics } \\
\text { (independent variable) }\end{array}$} \\
\hline Pearson correlation coefficient & $0 / 021$ & \\
\hline Significant level & $0 / 001$ & \\
\hline Number & 210 & \\
\hline
\end{tabular}

As above table shows the Pearson correlation coefficient for relationship between these two variables is $0 / 21$, that this correlation coefficient at $p<0 / 001$ is significant. It means that the $\left(H_{0}\right)$ hypothesis is not acceptable and the first hypothesis (hypothesis (1)) in this study will approve.

Hypothesis (2): there is a significant relationship between professional ethics and affective commitment among personnel.

Statistical hypothesis:

There is not significant relationship between professional ethics and affective commitment.

$H_{0}: B_{1}=0$

There is significant relationship between professional ethics and affective commitment among personnel's. $H_{1}: B_{1} \neq 0$

According to this fact that both variables have been measured in timed level, so the person correlation coefficient has been used to test this hypothesis and obtained results are as follow : Table 2. Related table to correlation coefficient between professional morals and affective commitment among personnel's.

\begin{tabular}{|l|c|l|}
\hline \multicolumn{2}{|l|}{ affective commitment } & \\
\cline { 1 - 2 } Pearson correlation coefficient & $0 / 0162$ & \\
\cline { 1 - 2 } Significant level & $0 / 01$ & \\
\hline Number & 210 & \\
\hline
\end{tabular}

As above table show the person correlation coefficient for relationship between these two variables is $0 / 16$, that this correlation coefficient at $p</ 01$ is significant. It means that the hypothesis (1) $\left(H_{0}\right)$ is not acceptable, so hypothesis (2) will approve in this study.

Hypothesis (3): there is significant relationship between professional ethics and continuous commitment among personnel's.

Statistical Hypothesis:

There is not significant relationship between professional ethics and continuous commitment among personnel's. $H_{0}=B_{1}=0$

There is significant relationship between professional ethics and continuous commitment 
among personals. $H_{1}: B_{1} \neq 0$

According to this fact that, both variables have been measured in timed level, so the person correlation coefficient used to test this hypothesis and obtained result are as follow:

Table 3. Related table to correlation coefficient between professional ethics and continuous commitment among personnel's

\begin{tabular}{|c|c|c|}
\hline \multicolumn{2}{|l|}{ Continuous commitment } & \multirow{4}{*}{ Professional ethics } \\
\hline Pearson correlation coefficient & $0 / 161$ & \\
\hline Significant level & $0 / 01$ & \\
\hline Number & 210 & \\
\hline
\end{tabular}

As above table show the person correlation coefficient for relationship between these two variables is $0 / 16$, that this correlation coefficient at $p<0 / 01$ is significant. It means that the hypothesis (1) $\left(H_{0}\right)$ is not acceptable, so hypothesis (3) will approve in this project.

Hypothesis (4): there is significant relationship between professional ethics and continuous commitment among personnel's.

Statistical Hypothesis:

There is not significant relationship between professional ethics and continuous commitment among personnel's. $H_{0}=B_{1}=0$

There is significant relationship between professional ethics and continuous commitment among personals. $H_{1}: B_{1} \neq 0$

According to this fact that, both variables have been measured in timed level, so the person correlation coefficient used to test this hypothesis and obtained result are as follow:

Table 3. Related table to correlation coefficient between professional ethics and continuous commitment among personnel's.

\begin{tabular}{|l|c|l|}
\hline Continuous commitment & \multirow{3}{*}{ Professional ethics } \\
\hline Pearson correlation coefficient & $0 / 163$ & \\
\hline Significant level & $0 / 01$ & \\
\hline Number & 210 & \\
\hline
\end{tabular}

As above table show the person correlation coefficient for relationship between these two variables is $0 / 16$, that this correlation coefficient at $p<0 / 01$ is significant. It means that the hypothesis (1) $\left(H_{0}\right)$ is not acceptable, so hypothesis (4) will approve in this project.

The brief results of findings related to project's hypotheses:

The result of this study showed that, all of the project's hypotheses were accepted. It means that, there is significant relationship between professional morals (independent variable) and organizational commitment (dependent variable) and its dimension's from the viewpoint of Allen and Meyer (affective commitment, continuous commitment and normative 
commitment).

\section{Conclusion}

Professional people and those working in acknowledged professions exercise specialist knowledge and skill. How the use of this knowledge should be governed when providing a service to the public can be considered a moral issue and is termed professional ethics.

Professional Values and Ethics are a set of moral principles and standards of conduct, supporting the moral prestige of professional groups in society. The tasks of professional ethics are to identify moral standards and assessments, judgments and concepts, characterizing people as representatives of a particular profession. Professional ethics develops norms, standards, requirements, typical to certain activities.

Ethics is designed to educate people, to help them to behave properly with others, to communicate at the workplace, etc. Professional ethics taught to follow the measurement standards of morality, adopted in order to regulate human behavior. These are the standards employees must navigate. Aligning themselves to these values, an employee should cultivate the appropriate personal qualities.

\section{References:}

1) Allen, N.J. \& Meyer, J.P., (1990), The Measurement and Antecedents of Affective, Continuance and Normative Commitment to the Organization, Journal of Occupational Psychology, vol.63, pp. 1-18

2) Chadwich Ruth, "Professional Ethics" in: Routledge Encyclopedia of Philosophy,1998.

3) Feldman.D et al. (2011). Affective organizational commitment and citizenship behavior: Linear and non-linear moderating effects of organizational tenure Original Research Article Journal of Vocational Behavior. Available at http://www.sciencedirect.com.

4) Kalshoven, K.et al. (2011), Ethical leadership at work questionnaire (ELW): Development and validation of a multidimensional measure Original Research Leadership Quarterly ,vol.22, pp51-69

5) Meyer, J.P. \& Allen, N.J. (1997). Commitment in The Workplace, Thousand Oaks, CA: Sage Publications.

6) Meyer, J.P., Allen, N.J. \& Larissa, T. (1998). Commitment in a Changing World of work, Canadian Psychology, Vol. 39, Is. 1/2, pg. 82.

7) Meyer, J.P., Paunonen, S.V., Gellatly, I.R., Goffin, R.D. \& Jackson, D.N. (1989).Organizational Commitment and Job Performance: It's The Nature of The Commitment That Counts, Journal of Applied Psychology, and vol. 74, pp. 152-156.

8) Nair.p \& Kamalanabhan,T.(2011). Predicting unwillingness to report ethical infractions of peers: A moderated mediation approach Original Research IIMB Management Review, vole 23, pp 81-90 
9) Romzek, B.S. (1990), Employee Investment and Commitment: The Ties That Bind, Public Administration Review, Vol. 50, pp. 374-382.

10) Simola,K.\& Barling.J\& Turner.N(2010). Transformational leadership and leader moral orientation: Contrasting an ethic of justice and an ethic of care Original Research Article The Leadership Quarterly, vol21.pp179-188

11) Valentine.s. (2010). Human resource management, ethical context, and personnel consequences: A commentary essay Original Research Article.vol.2010, pp 908-910 